\title{
Establishment of the Fatigue Curve Model Based on Stress Ratio
}

\author{
Liang Zhu ${ }^{1, a}$, Yiliang Zhang ${ }^{1, b}$, Xiaohui $\mathrm{Li}^{1, \mathrm{c}}$, Hongbo Suo ${ }^{2, \mathrm{~d}}$
}

${ }^{1}$ College of Mechanical Engineering and Applied Electronics Technology Beijing University of Technology, Beijing, China

\author{
${ }^{2}$ Beijing Aeronautical Manufacturing Technology Research Institute, Beijing, China \\ azlymtf@126.com, ${ }^{\mathrm{b}} 421046642 @ q q . c o m,{ }^{\mathrm{c}} 761789358 @ q q . c o m,{ }^{\mathrm{d}}$ suohb@126.com
}

Keywords: Stress Ratio, Fatigue Life, Fatigue Limit, R-S-N Mathematical Models

\begin{abstract}
Stress ratio has important effect on fatigue performance. For the influence of stress ratio o fatigue life, fatigue tests of Titanium alloy produced by rapid manufacturing(Ti alloy by RM) samples were carried out under three kinds of stress ratio( $R=0.5 、 R=0.06 、 R=-1)$, to draw three fatigue limits and $3 S-N$ curves of "stress amplitude life model ". Based on the integral relationship of the crack growth rate and fatigue life, considering both of mathematical models of fatigue life, a systematic investigation of the relationship between stress ratio $(R)$ and fatigue life curve $(S-N)$ was performed to build the fatigue life mathematical mode $(R-S-N)$. According to the modified formula proposed in this paper, the establishment of $R-S-N$ mathematical models, applicable for Ti alloy by RM materials. The result showed that "stress amplitude" model can accurately predict moderate fatigue life. The predictive value of proposed $R-S-N$ mathematical models were in better agreement with the experimental values, it can accurately predict the fatigue curve under any stress ratio in engineering.
\end{abstract}

\section{Introduction}

Conventional method of evaluated fatigue property of metal is determining $S-N$ curve(fatigue curve) or fatigue limit by experiment under certain stress ratio and obtained stress life curve equation at the same time. But in actual engineering, the material is bore complex loading, the stress ratio changed between $[-1,1]$. For Titanium alloy welding structures, stress ratio changed greatly affect the fatigue life and the material fatigue limit. So the stress-life equation of stress ratio as variable is obtained has important significance in theory and application.

About the influence of stress ratio on material fatigue performances, a lot of research had been done by researchers at home and abroad[1,2]. XUE[3] thought that stress ratio was important for fatigue life by fatigue test of titanium alloy under different stress ratio; ISHIHARA[4] studied the influence of stress ratio on the material fatigue life and crack propagation. But there were fewer studies on $R-S-N$ curve.

The relationships of stress ratio and $S-N$ curve were established in this paper. Based on the integral relationship of the crack growth rate and fatigue life, considered mathematical models of fatigue life, this paper built the fatigue life mathematical mode $(R-S-N)$. Fatigue tests of Titanium alloy produced by rapid manufacturing ( $\mathrm{Ti}$ alloy by RM ) samples were carried out under three kinds of stress ratio( $R=0.5 、 R=0.06 、 R=-1)$, to draw three fatigue limits and $3 S-N$ curves of "stress amplitude life model ". To verify applicability of the mathematical model of $R-S-N$ for Ti alloy by RM.

\section{R-Sa-N Model Based on Power Function}

In order to quantitative evaluation of the influence of stress ratio on $S-N$ curve, according to the literature[5], this paper introduced the influence of stress ratio on life by the mathematical model of crack propagation rate. Paris mathematical model of crack propagation rate as follows:

$$
d a / d N=C \Delta K^{m} .
$$


In formula, $d a / d N \longrightarrow$ crack propagation rate, $\Delta K \longrightarrow$ stress intensity factor, $C, m-$ the parameters of the crack propagation properties related to materials. Some studies had shown that the parameters $C$ and $m$ is correlated to stress ratio. When the stress ratio increased, Parameter $C$ increased and Parameter $m$ reduced[6,7]. So influence function was expressed as:

$$
d a / d N=C(R) \Delta K^{m(R)} .
$$

For unilateral crack of fatigue specimens, the formula could be expressed as follows:

$$
\Delta K=Y S_{a} \sqrt{\pi a} \text {. }
$$

In formula, $Y \longrightarrow$ geometric factor, depended on the ratio of crack length and the specimen width. Formula (3) was substitute into formula (2), integral of Specimen crack length from $\left[\mathrm{a}_{0}-\mathrm{a}_{\mathrm{f}}\right]$, integral of life from $[0-\mathrm{N}]$,

$$
\int_{a_{0}}^{a_{f}} a^{-\frac{m(R)}{2}} d a=\int_{0}^{N} C(R)\left(Y S_{a} \sqrt{\pi}\right)^{m(R)} d N
$$

Transformed formula (4) could be gotten

$$
-\frac{m(R)-2}{2} \cdot \frac{a_{f}^{-\frac{m(R)-2}{2}}-a_{0}^{-\frac{m(R)-2}{2}}}{C(R)(Y \sqrt{\pi})^{m(R)}}=S_{a}^{m(R)} N \text {. }
$$

Maked the left of the formula (5) was equal to $D(R)$, so $D(R)=S_{a}^{m(R)} N$, the opposite side of the equation was taken logarithm, the formula (5) was expressed as

$\lg N=\lg D(R)-m(R) \lg S_{a}$.

The formula (6) was contrasted the formula (7)

$\lg N=a-b \lg S_{a}$.

We could find that there is a function relationship parameters and stress ratio in $S$ - $N$ curve equation. Could be expressed as $a \propto \lg D(R), b \propto m(R)$, so the formula(6) could be expressed as

$\lg N=a(R)-b(R) \lg S_{a}$.

The formula (8) was taken exponential

$$
S_{a}^{b(R)} N=10^{a(R)}
$$

According to the results of fatigue tests, we could get different $\left(a_{i}, b_{i}\right)$ from different $S-N$ curve at the different stress ratios. We could get $a(R), b(R)$ by linear regression calculation. Finally, $R-S_{a}-N$ curve were determined.

\section{Experimental}

Experimental materials and experimental methods. Experiment with Ti alloy by RM as the research object, it's tensile strength of $1050 \mathrm{MPa}$. Considered the Ti alloy by RM sample in actual engineering by tension tension stress and tension-compression stress, three stress ratio $(R=0.5$ 、 $R=0.06 、 R=-1$ ) were used, fatigue test were done by the QBR - 100 microcomputer control high frequency fatigue test machine. Loading way was axial loading, loading waveform was sine wave. Group method was used in long life area, the up-and-down method was adopted in the fatigue limit.

The fatigue limit results under different stress ratio. The fatigue limit of material was got by the up-and-down method. Cycle cardinal $N_{0}=10^{7}$. The stress difference of the stress ratio $R=0.5, R$ $=0.6$ were $27.5 \mathrm{MPa}$, the stress difference of the stress ratio $R=-1$ were $10 \mathrm{MPa}$. They met the requirements of the up-and-down method. As shown in figure 1 for respectively up-and-down method results under different stress ratio. 

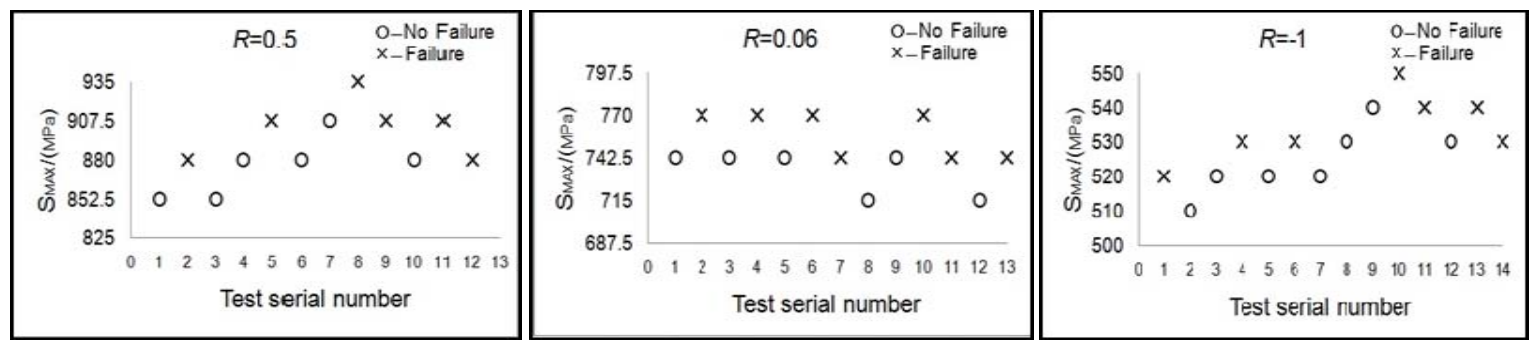

Fig. 1 Fatigue limit paired up and down figure with $R=0.5, R=0.06, R=-1$

Coefficient of variation of regulation[8] when confidence was equal to $95 \%$ and error limit was equal to $5 \%$ was evaluation benchmark. When coefficient of variation of the actual less than coefficient of variation of regulation, we thought the test was effective. All fatigue limit results were shown in table 1 .

Table 1 All the results of the fatigue limit

\begin{tabular}{ccccccc}
\hline$R_{\mathrm{j}}$ & $\begin{array}{c}\text { Number of } \\
\text { Valid } \\
\text { Sample }\end{array}$ & $\begin{array}{c}\text { Pairing } \\
\text { Number }\end{array}$ & $\begin{array}{c}\text { Fatigue } \\
\text { Limit } \\
/ \mathrm{MPa}\end{array}$ & $\begin{array}{c}\text { Standard } \\
\text { Deviation } \\
\text { /MPa }\end{array}$ & $\begin{array}{c}\text { Coefficient } \\
\text { Variation }\end{array}$ & $\begin{array}{c}\text { Regulation } \\
\text { Coefficient } \\
\text { Variation }\end{array}$ \\
\hline 0.5 & 12 & 6 & 889.17 & 20.7 & 0.023 & 0.040 \\
\hline 0.06 & 13 & 6 & 747.08 & 14.2 & 0.019 & 0.040 \\
\hline-1 & 14 & 7 & 529.29 & 9.76 & 0.018 & 0.048 \\
\hline
\end{tabular}

Experimental results of group method under different stress ratio. In order to get the $S-N$ curve under different stress ratio, fatigue test under stress ratio $R=0.5$ chose four groups stress level, the number of effective sample was 22. Fatigue test under stress ratio $R=0.06$ chose three groups stress level, the number of effective sample was 14. Fatigue test under stress ratio $R=-1$ chose three groups stress level, the number of effective sample was 19. The test results were shown in table 2.

Table 2 Experimental data with the grouped method

\begin{tabular}{|c|c|c|c|c|c|c|}
\hline$R$ & $S_{\max }$ & $\lg S_{\max }$ & $S_{a}$ & $\lg S_{a}$ & $\lg N$ & $n$ \\
\hline \multirow{4}{*}{0.5} & 990 & 2.9956 & 247.5 & 2.3936 & 5 & 6 \\
\hline & 962.5 & 2.9834 & 240.6 & 2.3813 & 5.19 & 7 \\
\hline & 935 & 2.9708 & 233.8 & 2.3688 & 6.09 & 5 \\
\hline & 907.5 & 2.9578 & 226.9 & 2.3558 & 6.51 & 4 \\
\hline \multirow{3}{*}{0.06} & 880 & 2.9445 & 413.6 & 2.6166 & 5.33 & 6 \\
\hline & 852.5 & 2.9307 & 400.7 & 2.6028 & 5.66 & 4 \\
\hline & 825 & 2.9165 & 387.8 & 2.5886 & 5.94 & 4 \\
\hline \multirow{3}{*}{-1} & 600 & 2.7782 & 600 & 2.7782 & 4.57 & 7 \\
\hline & 560 & 2.7482 & 560 & 2.7482 & 4.82 & 6 \\
\hline & 550 & 2.7404 & 550 & 2.7404 & 4.88 & 6 \\
\hline
\end{tabular}

Table 3 Equations of $S_{a}-N$ curve with different stress ratio

\begin{tabular}{cccc}
\hline$R$ & Equations of $S_{a}-N$ Curve & $\mathrm{a}$ & $\mathrm{b}$ \\
\hline 0.5 & $S_{a}^{43.22} N=10^{108.35}$ & 108.35 & 43.22 \\
0.06 & $S_{a}^{21.8} N=10^{62.37}$ & 62.37 & 21.8 \\
-1 & $S_{a}^{8.24} N=10^{27.47}$ & 27.47 & 8.24 \\
\hline
\end{tabular}




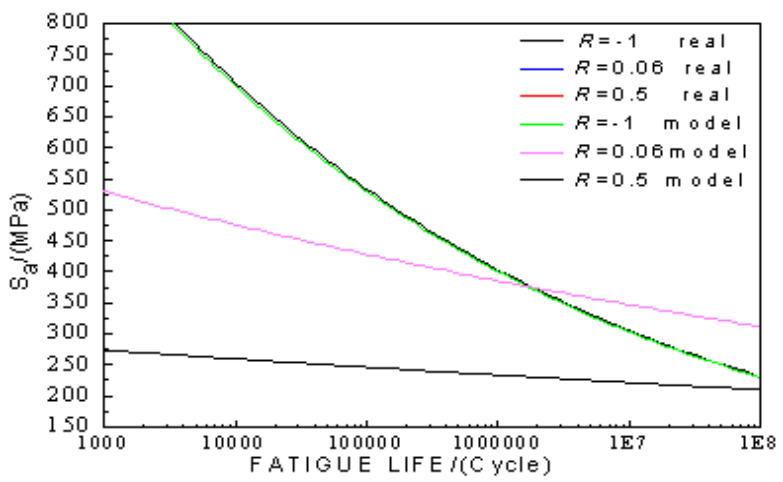

Fig. $2 S_{a}-N$ curves of three stress ratio

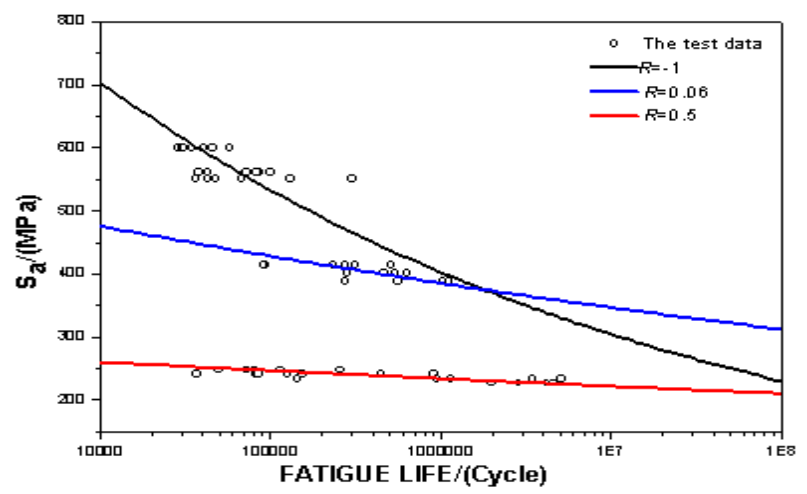

Fig. $3 S_{a}-N$ curves of model and real

On double logarithm coordinates, there was a linear relationship between $\lg S_{a}$ and $\lg N$. Relation could be expressed as: $\lg N=a-b \lg S_{a}$ or $S_{a}^{b} N=A$ Test data points $\left(\lg S_{a 1}, \lg N_{1}\right), \quad\left(\lg S_{a 2}\right.$, $\left.\lg N_{2}\right), \ldots\left(\lg S_{a i}, \lg N_{i}\right)$ was fitted used the least squares fitting. Undetermined parameters $a, b$ and $\mathrm{A}$ could be gotten by the least square method, fatigue curve equation was determined by parameters $a, b$ and A. Curve equation was listed in table 3 . Curve was shown in figure 2 .

\section{Established Ti Alloy by RM R-Sa-N Curve Equation}

The coefficient of S-N curve under three groups stress ratio in table 3. Respectively stress ratio and a were fitted and stress ratio and $b$ were fitted. Calculation results show that the parameters of $a$ and $\mathrm{b}$ and stress ratio $\mathrm{R}$ accord with binomial function form. The calculation results were shown below : $a(R)=47.72 \times R^{2}+77.78 \times R+57.53 . b(R)=23.93 \times R^{2}+35.28 \times R+19.60$

\section{Discussion}

The properties of the $\boldsymbol{S}_{\boldsymbol{a}} \boldsymbol{- N}$ curve. As shown in figure 2, (1) life was inversely proportional to the stress ratio in $S_{a}-N$ model. From mathematical explanation, stress amplitude and maximum stress had the following relations: $S_{a}=(1-R) S_{\max } / 2$, stress ratio was inversely proportional to the stress amplitude with the same maximum stress, the smaller the stress ratio, the greater the stress amplitude. (2) Gradient of $S a-N$ curve was inversely proportional to the stress ratio. Under the condition of equal stress difference $\left(\Delta \mathrm{S}_{\mathrm{a}}\right)$, stress ratio is lower, the greater the change of life. For example, stress amplitude reduced from $500 \mathrm{MPa}$ to $450 \mathrm{MPa}$, the fatigue life rose by $2.35 \times 10^{5}$ when the stress ratio $R=-1$. The fatigue life increased by $3.05 \times 10^{4}$ when the stress ratio $R=$ 0.06 ,them difference almost decuple.

The applicable scope of mathematical model. According to the figure 2 shown, Stress amplitude life curve was still falling when the fatigue life was more than $10^{7}$. There was no horizontal asymptote, so it couldn't reflect the fatigue limit. It Shown that stress amplitude curve was more suitable for the prediction of middle life region $\left(\mathrm{N}<10^{6}\right)$. Life and stress ratio kept direct proportion when the model introduced variable $R$.

The comparison of model curve and real curve. Compared mathematical model $R-S-N$ of established in this paper with the $S-N$ curve of experimental measurement. The result was shown in figure 3. Discovered by figure 3 that theory model curve of $S_{a}-N$ and measured curve of $S_{a}-N$ were almost consistent. Theoretical model could accurately reflect the fatigue life under different stress ratio. It was practicability of engineering.

\section{Conclusion}

(1)On the basis of Titanium alloy produced by rapid manufacturing material fatigue test results, mathematical model of $R-S-N$ was set up:

Stress amplitude life model: $S_{a}^{23.93 \times R^{2}+35.28 \times R+19.60} N=10^{47.72 \times R^{2}+77.78 \times R+57.53}$ 
Analysis shown that the models could predict the fatigue life under different stress ratio, the engineering practicality of the model had been verified.

(2) $R-S_{a}-N$ model could be accurately predicted fatigue life of medium fatigue life area. Due to the curve trend to infinitely downward, it couldn't reflect the fatigue limit.

\section{Reference}

[1] H.X.Cai, H.Cheng and J.X.Sun: Shanxi Architecture,Vol.33(2007) No 25, p.102.In Chinese

[2]S.W.Xu,M.S.Dong and Z.J.Hu:Journal of Hefei University of Technology,Vol.31(2008) No 9, p.1506. In Chinese

[3]H.Q.Xue, H.Tao and R.P.Shao: Transactions of Nonferrous Metals Society of China,Vol. 18(2008) No 3, p.499.

[4]S.Ishihara, A.J.Mcevily and M.Sato:International Journal of Fatigue,Vol.31(2009) No 11,p.1788.

[5]J.J.Xiong:Fatigue and Fracture Reliability Engineering(National Defense Industry Press,China 2008),p.60.

[6]K.Q.Wang, R.P.Xu and J.H.Lin: Journal of Aerospace Power, Vol. 24(2009) No 9, p.2012. In Chinese

[7]R.P.Xu, S.L.Li and K.Q.Wang:Engineering Mechanics, Vol.2005,22(2): No p.6-10. In Chinese

[8] Z.T.Gao and J.J.Xiong:Fatigue Reliability(Beihang University Press ,China 2000),p.293. 